\section{BMJ Open \\ Respiratory \\ Research}

\title{
Productivity losses in chronic obstructive pulmonary disease: a population-based survey
}

\author{
Marta Erdal, ${ }^{1}$ Ane Johannessen, ${ }^{2}$ Jan Erik Askildsen, ${ }^{3}$ Tomas Eagan, ${ }^{1,4}$ \\ Amund Gulsvik, ${ }^{4}$ Rune Grønseth ${ }^{1,4}$
}

To cite: Erdal $M$,

Johannessen A, Askildsen JE, et al. Productivity losses in chronic obstructive pulmonary disease: a population-based survey. BMJ Open Resp Res 2014;1: e000049. doi:10.1136/ bmjresp-2014-000049

- Additional material is available. To view please visit the journal (http://dx.doi.org/ 10.1136/bmjresp-2014000049)

Received 21 May 2014 Revised 23 September 2014 Accepted 26 October 2014

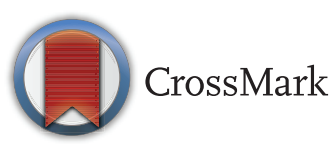

${ }^{1}$ Department of Thoracic Medicine, Haukeland University Hospital, Bergen, Norway

${ }^{2}$ Centre for Clinical Research, Haukeland University Hospital, Bergen, Norway ${ }^{3}$ Department of Economics, University of Bergen, Bergen, Norway

${ }^{4}$ Department of Clinical Science, University of Bergen, Norway

Correspondence to Dr Rune (Nielsen) Grønseth; nielsenrune@me.com

\section{ABSTRACT}

Objectives: We aimed to estimate incremental productivity losses (sick leave and disability) of spirometry-defined chronic obstructive pulmonary disease (COPD) in a population-based sample and in hospital-recruited patients with COPD. Furthermore, we examined predictors of productivity losses by multivariate analyses.

Methods: We performed four quarterly telephone interviews of 53 and 107 population-based patients with COPD and controls, as well as 102 hospital-recruited patients with COPD below retirement age. Information was gathered regarding annual productivity loss, exacerbations of respiratory symptoms and comorbidities. Incremental productivity losses were estimated by multivariate quantile median regression according to the human capital approach, adjusting for sex, age, smoking habits, education and lung function. Main effect variables were COPD/control status, number of comorbidities and exacerbations of respiratory symptoms.

Results: Altogether $55 \%, 87 \%$ and $31 \%$ of populationbased COPD cases, controls and hospital patients, respectively, had a paid job at baseline. The annual incremental productivity losses were $5.8(95 \% \mathrm{Cl} 1.4$ to $10.1)$ and $330.6(95 \% \mathrm{Cl} 327.8$ to 333.3$)$ days, comparing population-recruited and hospital-recruited patients with COPD to controls, respectively. There were significantly higher productivity losses associated with female sex and less education. Additional adjustments for comorbidities, exacerbations and $\mathrm{FEV}_{1} \%$ predicted explained all productivity losses in the population-based sample, as well as nearly $40 \%$ of the productivity losses in hospital-recruited patients.

Conclusions: Annual incremental productivity losses were more than 50 times higher in hospital-recruited patients with COPD than that of population-recruited patients with COPD. To ensure a precise estimation of societal burden, studies on patients with COPD should be population-based.

\section{INTRODUCTION}

Chronic obstructive pulmonary disease (COPD) is the third most frequent illness causing death, and the WHO has estimated

\section{KEY MESSAGES}

The societal burden of productivity losses in chronic obstructive pulmonary disease (COPD) is considerable and can, to a large degree, be explained by exacerbations and comorbid diseases.

Patients with COPD recruited from hospital clinics have much higher productivity losses than Patients with COPD recruited from population-based samples.

Economic evaluations should not be based on effectiveness studies recruiting patients from hospital or private practice as this will lead to biased results.

that it will keep this position in year 2030 as well. ${ }^{1}$ COPD is a chronic disease where the patients' health status usually deteriorates over time and which imposes considerable treatment-related costs on healthcare systems worldwide. ${ }^{23}$ Having COPD affects the productivity of the diseased, often measured as short and long-term absenteeism. ${ }^{4}$

Estimates of productivity losses can serve as input when creating disease models simulating future impact of a disease, and may add to economic evaluations of treatment options. ${ }^{5}$ Studies with control groups are able to estimate the incremental, or excessive productivity losses, associated with a disease. That is, the increase in productivity losses associated with adding the index disease to a baseline level of productivity losses. ${ }^{6}$

The usefulness of economic evaluations and estimates of productivity losses depend on the correct identification of COPD cases in a representative population. However, the first economic evaluations of new treatment options are often 'piggy-backed' on randomised controlled studies, with rigorous recruitment criteria in selected populations (specialist practices, hospital outpatient clinics). However, in order to serve as a 
decision-making aid, productivity losses of COPD should be investigated in population-based samples where COPD is diagnosed by screening with postbronchodilation spirometry.

A few studies have estimated productivity losses of COPD in a general population. ${ }^{4}{ }^{7-13}$ Most of these studies did not verify COPD by spirometry ${ }^{7812} 13$ or had scarce data on productivity losses. ${ }^{9-11}$ The PLATINO study compared employment rates in patients aged 40 years or older with postbronchodilator COPD to patients without COPD. They showed that $42 \%$ of the patients and $57 \%$ of the controls reported having a paid job during the past 12 months. ${ }^{10}$ No quantitative estimates of productivity loss were reported from the PLATINO study. One Swedish study calculated productivity losses in a general population screened by spirometry. However, this study did not include a control group and no information was available regarding comorbidities or respiratory exacerbations. ${ }^{4}$

Thus, there is a paucity of studies on real productivity loss from COPD in a true population setting. To the best of our knowledge, no study has compared the productivity losses of population-derived COPD cases with patients recruited from a hospital clinic, which could serve to evaluate the usefulness of economic evaluations based on randomised controlled trials.

The study of COPD-related costs (EconCOPD) offers a unique opportunity to address these issues. EconCOPD was a prospective 12 months cost-of-illness study of population-based patients with and without COPD, where cases were detected by state-of-the art postbronchodilator spirometry. ${ }^{14}{ }^{15}$ The aim of the current paper was to estimate annual, incremental societal productivity losses due to COPD and examine predictors of these. The study also included a separate group of hospitalrecruited patients with COPD, enabling a comparison of productivity losses in population-based and hospitalrecruited individuals with COPD.

\section{METHODS}

EconCOPD was conducted between March 2005 and August 2006 at the Department of Thoracic Medicine, Haukeland University Hospital, Bergen, Norway. The Regional Committee for Medical and Health Research Ethics in Western Norway approved the study (approval REK Vest nr. 252.04). Some of the results were presented in a preliminary report at the European Respiratory Society annual conference in 2011.

\section{Study population}

EconCOPD consisted of three groups of participants from two sources: COPD cases and controls were recruited from a population-based cohort study, and additional patients with COPD were gathered from a patient register at Haukeland University Hospital. ${ }^{16}$ Details regarding the EconCOPD study population can be found in the online appendix and in previous publications.

For the current analyses, all participants were between 40 and 67 years of age. They were current and ex-smokers that had consumed at least the equivalent of 20 cigarettes/day for 2.5 years. COPD was defined as a postbronchodilator ratio of forced expiratory volume in $1 \mathrm{~s}$ $\left(\mathrm{FEV}_{1}\right)$ to forced vital capacity (FVC) less than 0.7 and an $\mathrm{FEV}_{1}$ less than $80 \%$ of predicted value according to age, sex and height. ${ }^{17}$ Postbronchodilator spirometry was performed according to ATS standards. ${ }^{18}$ The control subjects had $\mathrm{FEV}_{1} / \mathrm{FVC}>0.7$ and $\mathrm{FEV} 1 \%$ predicted $>80 \%$.

\section{Design}

At inclusion, all participants went through a face-to-face baseline interview where information concerning smoking habits, employment status and comorbidities was gathered. At 12, 24, 36 and 52 weeks, participants were interviewed by telephone, providing information regarding productivity losses (sick leave, disability pension) as well as exacerbations of respiratory symptoms. The latter were defined by an increase in two major symptoms (dyspnoea, sputum volume or sputum colour) or one major and two minor symptoms (cough, sore throat, nasal secretion, wheezing or asthaenia) for at least two consecutive days (modified Anthonisen criteria ${ }^{19}$ ). Comorbidities were evaluated by asking for the presence of conditions listed in the Charlson Comorbidity Index..$^{20}$ Modifying the cost-of-illness questionnaire from a comparable Swedish study, ${ }^{21}$ we developed questions regarding healthcare utilisation.

\section{Productivity losses}

Participants reported number of days with sick leave (irrespective of cause) since the preceding interview; these were added up for all four follow-up interviews and classified as 'sick leave days'. Number of days in disability pension was added from the baseline interview as well as the follow-up interviews ('disability days'). For patients receiving either graded sick leave or graded disability pension, we multiplied the number of days with the relevant percentage share. Disability days and sick leave days were added, and the resulting variable was named productivity loss.

\section{Statistics}

Bivariate analyses were conducted using parametric ( $\mathrm{t}$ tests, ANOVA) or non-parametric ( $\chi^{2}$, Kruskal Wallis, trend test, Spearman's correlation) tests where appropriate after assessing normality.

Data on productivity losses were truncated, that is, there was a large number of zeros and 365 days of lost productivity. Thus, the incremental, or excessive, productivity losses were estimated by median quantile regression analyses. $^{22}$ The principal models were one including population-recruited COPD cases and controls, and one with hospital-recruited patients with COPD and the population-recruited controls. The adjusted incremental productivity losses associated with 
COPD were identified by a categorical variable indicating case/control status. The regression coefficient of this latter variable reflects the change in productivity losses when 'adding' COPD to the baseline productivity loss in control subjects. All models were adjusted for sex, age, smoking habits and education. Additional models explored the effect of adding $\mathrm{FEV}_{1} \%$ predicted, number of comorbidities and number of exacerbations of respiratory symptoms.

All analyses were performed with Stata SE V.11 for Macintosh OSX (Stata Corp, College Station, Texas, USA).

\section{RESULTS}

Table 1 shows population characteristics and unadjusted productivity losses. In total, 53 COPD cases and 107 controls from the population-based sample completed 1 year of follow-up, as well as 102 hospital-recruited patients with COPD. There was no significant difference between the three groups with respect to gender, but both groups of COPD cases were older, and they had more exacerbations of respiratory symptoms and more comorbidities than the controls $(\mathrm{p}<0.01)$. An E-table 1 also shows the frequency of selected comorbid conditions and chronic respiratory symptoms. The controls had a larger percentage of university-educated people $(\mathrm{p}<0.01)$.

At baseline most population-recruited controls reported having a paid job $(87 \%)$, compared to fewer population-recruited $(55 \%)$ and hospital-recruited patients with COPD (31\%). Disability pension was most prevalent in the hospital-recruited COPD cases, and least prevalent among the control subjects.

There was considerable truncation of our main outcome variables. In total $56 \%, 25 \%$ and $5 \%$ of hospital-recruited patients with COPD, population-based COPD cases and controls, respectively, reported 365 days of lost productivity. Conversely, $41 \%$ and $38 \%$ of the population-recruited controls and population-based COPD cases had no productivity loss for the entire year. Only $8 \%$ of the hospital-recruited COPD cases had no productivity loss during the follow-up period. There was a significant trend that hospital-recruited COPD cases had the highest, while controls had the smallest number of lost days (test for trend, $\mathrm{p}<0.001$ ).

Bivariate analyses of productivity losses in the three participant groups (tables 2 and 3) showed that in all three groups women had higher productivity losses than men. In hospital-recruited patients with COPD, increased productivity losses were associated with lower education and lower $\mathrm{FEV}_{1} \%$ predicted, and number of comorbid conditions.

\section{Incremental analyses}

Table 4 shows the results of the median quantile regression analyses with number of days of lost productivity as the outcome. The coefficients for the COPD status show the incremental productivity losses associated with COPD when controlling for gender, age, education and smoking habits. That is, when we compared population-based COPD cases to controls, the presence of postbronchodilator COPD was related to an additional 5.8 (95\% CI 1.4 to 10.1) days of productivity loss. Hospital-recruited patients with COPD lost 330.6 (95\% CI 327.8 to 333.3) days when comparing control subjects. There were significantly higher productivity losses associated with the female sex and less education. When we added $\mathrm{FEV}_{1} \%$ predicted to these two models, the incremental productivity losses associated with COPD status became non-significant and 284.3 (95\% CI 267.4 to 301.2) days, comparing populationrecruited and hospital-recruited COPD cases to controls, respectively (E-table 2 ).

We also explored the effect of number of comorbid conditions and number of exacerbations of respiratory symptoms (table 5). This adjustment removed the effect of the COPD status for the comparison populationrecruited COPD cases and controls, and reduced the productivity losses for the hospital-recruited COPD cases by $5.5 \%$ (from 330 to 312 days). Adding one comorbid condition increased productivity losses by 5.0 (95\% CI 2.6 to 7.4 ) and 5.1 (95\% CI 3.2 to 7.1 ) days in the models analysing population-recruited and hospitalrecruited COPD cases, respectively. An increase of one exacerbation increased the productivity loss in the population-recruited sample, but to a lesser degree in the model including hospital-recruited patients with COPD. When we adjusted for $\mathrm{FEV}_{1} \%$ predicted values in similar analyses (E-table 3), the effect of comorbidities increased to 14.8 (95\% CI 8.1 to 21.5) days when comparing hospital-recruited patients with COPD to the controls. In this latter model, the annual productivity losses related to COPD were 204.5 (95\% CI 165.9 to 243.1) days, a reduction of $38 \%$ compared to the baseline model in table 4.

\section{DISCUSSION}

The annual incremental productivity losses incurred by population-based patients with COPD were 5.8 days, and increased by a factor of more than 50 when we compared them with patients recruited from a university hospital register. Our findings highlight that studies with patients recruited from hospital clinics provide biased estimates of disease burden in COPD.

When we explored the effects of pulmonary function, comorbidities and respiratory symptom exacerbations, the difference between population-derived estimates and estimates based on hospital-recruited patients with COPD persisted. Nevertheless, these variables were able to fully explain the productivity losses in COPD in a general population, and almost $40 \%$ of the productivity loss in hospital-recruited patients with COPD.

To the best of our knowledge, no other study has compared estimates of productivity losses when patients with COPD are recruited from different sources. Other 
Table 1 Characteristics of hospital-recruited and population-recruited COPD cases and population-recruited control patients below 67 years of age in the EconCOPD study

\begin{tabular}{|c|c|c|c|c|}
\hline & $\begin{array}{l}\text { Hospital-recruited } \\
\text { COPD cases }\end{array}$ & $\begin{array}{l}\text { Population-recruited } \\
\text { COPD cases }\end{array}$ & $\begin{array}{l}\text { Population-recruited } \\
\text { controls }\end{array}$ & Statistic \\
\hline $\mathrm{N}$ & 102 & 53 & 107 & \\
\hline Male, N (\%) & $57(56)$ & $30(57)$ & $54(50)$ & $\chi^{2}, p=0.662$ \\
\hline Age, mean years (SD) & $59(5.2)$ & $58(6.2)$ & $53(6.9)$ & ANOVA, $p<0.001$ \\
\hline Smoking status & & & & $\chi^{2}, p=0.054$ \\
\hline Current smoker, N (\%) & $41(40)$ & $31(58)$ & $57(53)$ & \\
\hline Former smoker, $\mathrm{N}(\%)$ & $61(60)$ & $22(42)$ & $50(47)$ & \\
\hline Education, $\mathrm{N}(\%)$ & & & & $\chi^{2}, p<0.001$ \\
\hline Primary & $36(35)$ & $22(42)$ & $20(19)$ & \\
\hline Secondary & $54(53)$ & $19(36)$ & $48(45)$ & \\
\hline University & $12(12)$ & $12(23)$ & $39(36)$ & \\
\hline $\mathrm{FEV}_{1} \%$ predicted, $\mathrm{N}(\%)$ & & & & $\chi^{2}, p<0.001$ \\
\hline$\geq 80 \%$ & & & $107(100)$ & \\
\hline$\geq 50 \%,<80 \%$ & $51(50)$ & $47(89)$ & & \\
\hline$\geq 30,<50 \%$ & $28(27)$ & $4(8)$ & & \\
\hline$<30 \%$ & $23(23)$ & $2(4)$ & & \\
\hline Mean $\mathrm{FEV}_{1} \%$ predicted (SD) & $47.0(12.6)$ & $65.5(12.6)$ & $94.3(8.33)$ & ANOVA, $p<0.001$ \\
\hline Median $\mathrm{FEV}_{1} \%$ predicted (IQR) & $50.7(29.7)$ & $68.4(13.3)$ & $93.1(10.1)$ & $\begin{array}{l}\text { Kruskal-Wallis } \\
\text { with ties, } \\
p<0.001 \text {; trend } \\
\text { test } p<0.001\end{array}$ \\
\hline \multicolumn{5}{|l|}{ Number of comorbid conditions } \\
\hline Mean (SD) & $1.5(1.7)$ & $1.0(0.9)$ & $0.7(1.0)$ & ANOVA, $p<0.001$ \\
\hline Median (IQR) & $1(2)$ & $1(1)$ & $0(1)$ & $\begin{array}{l}\text { Kruskal-Wallis } \\
\text { with ties, } \\
p=0.003 \text {; trend } \\
\text { test } p=0.001\end{array}$ \\
\hline \multicolumn{5}{|l|}{$\begin{array}{l}\text { Number of events of } \\
\text { exacerbations of respiratory } \\
\text { symptoms }\end{array}$} \\
\hline Mean (SD) & $6.8(6.5)$ & $3.5(7.3)$ & $0.8(1.6)$ & ANOVA, $p<0.001$ \\
\hline Median (IQR) & $5.5(10)$ & $1(4)$ & $0(1)$ & $\begin{array}{l}\text { Kruskal-Wallis } \\
\text { with ties, } \\
p=0.001 \text {; trend } \\
\text { test } p<0.001\end{array}$ \\
\hline $\begin{array}{l}\text { Employment status at baseline, } \\
N(\%)\end{array}$ & & & & $\chi^{2}, p<0.001$ \\
\hline Paid job & $32(31)$ & $29(55)$ & $93(87)$ & \\
\hline Retired & $1(1)$ & $4(8)$ & $4(4)$ & \\
\hline Disability pension & $66(65)$ & $16(30)$ & $8(7)$ & \\
\hline Other* & $3(3)$ & $4(8)$ & $2(2)$ & \\
\hline \multicolumn{5}{|l|}{ Days in sick leave during 1 year } \\
\hline Total number & 1287.7 & 1023.5 & 1676.5 & \\
\hline Mean (SD) & $12.6(30.0)$ & $19.3(55.4)$ & $15.7(36.4)$ & ANOVA, $p=0.59$ \\
\hline Median (IQR) & $0(5)$ & $0(3)$ & $1(14)$ & $\begin{array}{l}\text { Kruskal-Wallis } \\
\text { with ties, } p=0.05 ; \\
\text { trend test } p=0.03\end{array}$ \\
\hline \multicolumn{5}{|l|}{$\begin{array}{l}\text { Days with disability pension } \\
\text { during } 1 \text { year }\end{array}$} \\
\hline Any disability pension, $\mathrm{N}(\%)$ & $69(68)$ & $19(36)$ & $9(8)$ & $\chi^{2}, p<0.001$ \\
\hline Total number & 23322 & 5344.3 & 2504 & \\
\hline Mean (SD) & $228.6(170.3)$ & $100.8(156.3)$ & $23.4(83.1)$ & ANOVA, $p<0.001$ \\
\hline Median (IQR) & $365(365)$ & $0(256)$ & $0(0)$ & $\begin{array}{l}\text { Kruskal-Wallis } \\
\text { with ties, } \\
p<0.001 \text {; trend } \\
\text { test } p<0.001\end{array}$ \\
\hline
\end{tabular}




$\begin{array}{llll}\text { Hospital-recruited } & \begin{array}{l}\text { Population-recruited } \\ \text { COPD cases }\end{array} & \begin{array}{l}\text { Population-recruited } \\ \text { COPD cases }\end{array} & \text { controls }\end{array}$

\begin{tabular}{|c|c|c|c|c|}
\hline \multicolumn{5}{|l|}{$\begin{array}{l}\text { Days with productivity loss } \\
\text { during } 1 \text { year }\end{array}$} \\
\hline Total number & 24609.7 & 6367.8 & 4180.5 & \\
\hline $\begin{array}{l}\text { Zero days of productivity loss, } \\
\mathrm{N}(\%)\end{array}$ & $8(8)$ & $20(38)$ & $44(41)$ & $\chi^{2}, p<0.001$ \\
\hline $\begin{array}{l}365 \text { days of productivity loss, } \\
\mathrm{N}(\%)\end{array}$ & $57(56)$ & $13(25)$ & $5(5)$ & $\chi^{2}, p<0.001$ \\
\hline Mean (SD) & $241.3(158.7)$ & $120.2(158.5)$ & $39.1(86.6)$ & ANOVA, $p<0.001$ \\
\hline Median (IQR) & $365(320)$ & 9 (329.3) & $5(26)$ & $\begin{array}{l}\text { Kruskal-Wallis } \\
\text { with ties, } \\
p=0.0001 \text {; trend } \\
\text { test } p<0.001\end{array}$ \\
\hline
\end{tabular}

Trend tests for hospital patients<population-based patients<control subjects.

*Students, unemployed, homemakers.

ANOVA, analysis of variance; COPD, chronic obstructive pulmonary disease; EconCOPD, COPD-related costs; FEV ${ }_{1}$, forced expiratory volume in $1 \mathrm{~s}$.

studies have provided estimates of productivity losses. Darkow et $a l$ analysed a US database with claims from 550000 employees. They compared matched controls to COPD and found that $23 \%$ of 1355 identified COPD cases made at least one disability claim, versus $7 \%$ of control subjects. These productivity losses seem low, but patients without a job were not included. Furthermore, COPD is underdiagnosed, particularly in less severe disease, ${ }^{23}{ }^{24}$ even though they utilise a considerable amount of healthcare resources. ${ }^{25}$ Finally, by relying on diagnosis codes on claims, patients who did not utilise healthcare resources were ignored and the productivity loss per patient might be over-estimated.

The obstructive lung disease in Northern Sweden study (OLIN) has provided costs of productivity losses for patients with COPD from a general population. They found that the annual work absence was 22.6, $0,0.71$ and 1.14 days; and early retirement $15.2 \%, 6.9 \%, 4.1 \%$ and $0.2 \%$ in GOLD stages IV, III, II and I, respectively. ${ }^{4}$ However, the OLIN study did not include a control group. The consequential inability to estimate incremental productivity losses raises the questions of which part of the costs were actually causally related to COPD, and whether all costs were captured. Neither the OLIN studies, nor the study by Darkow et al investigated the effect of comorbidities or exacerbations of respiratory symptoms. ${ }^{4}$

Exacerbations of respiratory symptoms and comorbidities were able to explain most of the productivity losses in patients with COPD from our population-based sample. In the model with hospital-recruited COPD cases, the number of productivity loss days were reduced, but remained significant. Quite surprisingly, exacerbations of respiratory symptoms only contributed marginally to the latter model. This finding might reflect that in a severely diseased population with a large number of patients with 365 days of lost productivity, there are fewer days available to be lost to exacerbations than in the population-based sample. Comorbidities might be more likely to influence permanent disability than the more transient effect of exacerbations. Furthermore, the effects of exacerbations and comorbidities might indicate that the effect of reducing exacerbations is even stronger in population-based samples than

Table 2 Days of lost productivity in hospital-recruited COPD cases, population-recruited COPD cases and population-recruited control subjects by gender, smoking status and education

\begin{tabular}{|c|c|c|c|c|c|c|c|}
\hline & \multicolumn{2}{|l|}{ Gender } & \multicolumn{2}{|c|}{ Smoking status } & \multicolumn{3}{|l|}{ Education } \\
\hline & Men & Women & Current & Ex & Primary & Secondary & University \\
\hline $\begin{array}{l}\text { Hospital-recruited COPD cases, } \\
\text { median (IQR) }\end{array}$ & $314(355)^{\star}$ & $365(140.5)$ & 318 (353) & 365 (278) & $365(120)^{\star}$ & 365 (337) & $16.5(362)$ \\
\hline $\begin{array}{l}\text { Population-recruited COPD } \\
\text { cases, median (IQR) }\end{array}$ & $2.5(28)^{\star}$ & $132.5(365)$ & 7 (295) & 37 (365) & $4(365)$ & 28 (332) & $4(76)$ \\
\hline $\begin{array}{l}\text { Population-recruited controls, } \\
\text { median (IQR) }\end{array}$ & $1.5(8)^{\star}$ & $8(32)$ & $5(34)$ & $3.5(14)$ & 29 (202.5) & $5(16.5)$ & $1(14)$ \\
\hline
\end{tabular}


Table 3 Spearman's $r$ for correlations between days of lost productivity and age, FEV $\%$ predicted values, comorbidities and exacerbations of respiratory symptoms in hospital-recruited COPD cases, population recruited-COPD cases and population-recruited control subjects

\begin{tabular}{|c|c|c|c|c|}
\hline & Age & $\begin{array}{l}\mathrm{FEV}_{1}, \% \text { of } \\
\text { predicted }\end{array}$ & $\begin{array}{l}\text { Number of comorbid } \\
\text { conditions }\end{array}$ & $\begin{array}{l}\text { Number of events, } \\
\text { exacerbations of } \\
\text { respiratory symptoms }\end{array}$ \\
\hline $\begin{array}{l}\text { Hospital-recruited COPD } \\
\text { cases, Spearman's r }\end{array}$ & $r=0.154 ; p=0.12$ & $r=-0.390 ; p<0.001$ & $r=0.341 ; p<0.001$ & $r=0.071 ; p=0.478$ \\
\hline $\begin{array}{l}\text { Population-recruited COPD } \\
\text { cases, Spearman's r }\end{array}$ & $r=0.035 ; p=0.80$ & $r=-0.214 ; p=0.124$ & $r=0.28 ; p=0.039$ & $r=0.246 ; p=0.075$ \\
\hline $\begin{array}{l}\text { Population-recruited } \\
\text { controls, Spearman's r }\end{array}$ & $r=0.023 ; p=0.81$ & $r=-0.136 ; p=0.163$ & $r=0.156, p=0.108$ & $r=0.20, p=0.038$ \\
\hline
\end{tabular}

in hospital-recruited samples. Consequently, economic evaluations based on hospital-recruited patients from randomised controlled trials might underestimate the effect of reducing exacerbations on productivity losses and give less favourable cost-effectiveness measures when examining societal costs.

The major strength of the current study was the ability to estimate incremental productivity losses in a sample of patients with COPD recruited by screening a general population of ex-smokers and current-smokers by postbronchodilator spirometry. Instead of trying to identify the cause of each day of lost productivity, we estimated the effect on all-cause productivity loss by changing participant status from control to patient. Furthermore, the project was prospective and data were obtained by four interviews of trained staff during a full calendar year, at intervals minimising recall bias. ${ }^{26}$ Comprehensive data enabled us to include unique information regarding comorbidities as well as exacerbations of respiratory symptoms.

Certain potential limitations should be discussed. First, we excluded never-smoking patients and patients younger than 40 years of age. This was mainly to avoid confounding by patients with chronic asthma, and to ensure that smoking habits would not be the dominating difference between patients with COPD and controls. The COPD diagnosis was made primarily based on spirometry, but restricted to $\mathrm{FEV}_{1}$ less than $80 \%$ of predicted. Patients with overlap syndrome or chronic asthma were, as such, included. Second, we had a low number of population-recruited participants with severe and very severe airway obstruction. However, we found a significant association between increasing $\mathrm{FEV}_{1}$ and decreasing productivity losses. Third, participants in the

Table 4 Annual days of lost productivity in a general population and in a hospital population

\begin{tabular}{|c|c|c|}
\hline Covariate & $\begin{array}{l}\text { Population-recruited COPD cases and } \\
\text { controls }(\mathrm{N}=160) ;(95 \% \mathrm{CI})\end{array}$ & $\begin{array}{l}\text { Hospital recruited COPD cases and } \\
\text { population-recruited controls }(\mathrm{N}=209) ;(95 \% \mathrm{Cl})\end{array}$ \\
\hline \multicolumn{3}{|l|}{ COPD status } \\
\hline No COPD & Ref & Ref \\
\hline $\begin{array}{l}\text { COPD, FEV } 1<80 \% \\
\text { of predicted }\end{array}$ & $5.8(1.4$ to 10.1$)$ & 330.6 (327.8 to 333.3$)$ \\
\hline \multicolumn{3}{|l|}{ Sex } \\
\hline Male & Ref & Ref \\
\hline Female & 9.5 (5.7 to 13.3$)$ & 8.3 (5.9 to 10.6$)$ \\
\hline Age, per year & $0.06(-0.24$ to 0.37$)$ & $0.17(-0.03$ to 0.37$)$ \\
\hline \multicolumn{3}{|l|}{ Smoking habit } \\
\hline Current smoker & Ref & Ref \\
\hline Ex-smoker & $0.8(-3.3$ to 5.0$)$ & $1.0(-1.5$ to 3.4$)$ \\
\hline \multicolumn{3}{|l|}{ Education } \\
\hline University & Ref & Ref \\
\hline Secondary & $4.23(-0.3$ to 8.8$)$ & 5.0 (2.0 to 8.0$)$ \\
\hline Primary & $6.2(1.0$ to 11.5$)$ & 25.5 (22.1 to 28.9$)$ \\
\hline Constant & $-4.22(-20.7$ to 12.2$)$ & $-10.0(-20.7$ to 0.6$)$ \\
\hline
\end{tabular}


Table 5 Annual days of lost productivity in a general population and in a hospital population

\begin{tabular}{|c|c|c|}
\hline Covariate & $\begin{array}{l}\text { Population-recruited COPD cases and } \\
\text { controls }(\mathrm{N}=160) ;(95 \% \mathrm{CI})\end{array}$ & $\begin{array}{l}\text { Hospital-recruited COPD cases and } \\
\text { population-recruited controls } \\
(\mathrm{N}=209) ;(95 \% \mathrm{Cl})\end{array}$ \\
\hline \multicolumn{3}{|l|}{ COPD status } \\
\hline No COPD & Ref & Ref \\
\hline COPD, $\mathrm{FEV}_{1}<80 \%$ of predicted & $0(-5.2$ to 5.2$)$ & $312.4(305.4$ to 319.5$)$ \\
\hline Per added comorbidity & $5.0(2.6$ to 7.4$)$ & $5.1(3.2$ to 7.1$)$ \\
\hline $\begin{array}{l}\text { Per added exacerbation of } \\
\text { respiratory symptoms }\end{array}$ & $6.50(6.2$ to 6.8$)$ & $0.7(0.1$ to 1.3$)$ \\
\hline \multicolumn{3}{|l|}{ Sex } \\
\hline Male & Ref & Ref \\
\hline Female & 7.5 (3.0 to 12.0$)$ & $4.8(-0.6$ to 10.3$)$ \\
\hline Age, per year & $0.0(-0.4$ to 0.4$)$ & $0.1(-0.4$ to 0.6$)$ \\
\hline \multicolumn{3}{|l|}{ Smoking habit } \\
\hline Current smoker & Ref & Ref \\
\hline Ex-smoker & $0.0(-4.7$ to 4.7$)$ & $1.6(-4.0$ to 7.1$)$ \\
\hline \multicolumn{3}{|l|}{ Education } \\
\hline University & Ref & Ref \\
\hline Secondary & $6.5(1.3$ to 11.7$)$ & $3.9(-2.9$ to 10.8$)$ \\
\hline Primary & 8.5 (2.4 to 14.6$)$ & 27.6 (19.9 to 35.4$)$ \\
\hline Constant & $-6.5(-25.4$ to 12.4$)$ & $-7.0(-31.5$ to 17.5$)$ \\
\hline
\end{tabular}

current study were recruited from the city of Bergen, Western Norway and 11 surrounding municipalities, which is a rather small geographic area. However, a comparison between national Norwegian survey data for individuals older than 40 years of age with patients from the original cohort study that EconCOPD recruited from, was comparable. ${ }^{27}$ There might also be issues of selection bias, but the response rates were high, ${ }^{14}$ and non-response analyses have only shown that more elderly patients declined participation or were lost to follow-up, and that $\mathrm{FEV}_{1}$ was associated with mortality. ${ }^{27}$ Fourth, as in all studies based on self-reported data, there might be some degree of recall bias. To counter this, interviewers went through extensive training; there were comprehensive written interviewer guidelines and we chose a short recall period of 3 months combined with a prospective study design. Nevertheless, one might imagine that some degree of differential recollection of sick leave and comorbidities might exist, but what the effect would be on the results is more difficult to speculate on. Fifth, when we quantified productivity losses we used the human capital approach (HCA). There are alternative methods of estimating productivity losses, and some authors favour friction cost method (FCM) where the productivity losses are discounted based on the assumption that co-workers and un-employed, and structural changes to some degree compensate for absenteeism. ${ }^{6}$ We chose the HCA primarily because we also want to elucidate the burden of disease from the patient's point of view and, furthermore, the FCM might be less suitable in Norway due to very low unemployment rates. ${ }^{28}$
Sixth, our data did not include information regarding occupation. However, we did adjust for education, which might convey some similar information. Finally, we did not have data on presenteeism, that is, diminished working capability due to disease, which inevitably made our estimates conservative.

Our aims with the current analyses included a comparison of incremental productivity losses in populationbased COPD cases with those in hospital-recruited cases. A former analysis showed that the treatment-related costs of hospital-recruited patients with COPD were considerably higher than costs in population-based patients with COPD. ${ }^{15}$ That trend seemed to be even more evident when we estimated productivity losses. The initial economic evaluations that often guide implementation of new therapies are frequently based on phase 3 studies with rigid inclusion criteria, and patients who quite often are recruited from hospitals and private practices. $^{29}$ Thus, the current study sheds light on the validity of that approach, which approximates the incremental analysis with hospital-based patients with COPD and population-based controls. The considerable productivity loss in hospital-based COPD cases generates a larger potential for saving costs by reducing short-term or long-term disability, and serves as a bias. Thus, decision makers should be aware that this lack of external validity has implications for the credibility of costeffectiveness analyses that aim to estimate societal costs.

We have shown that in a population-based sample, COPD was associated with an annual excessive productivity loss of 5.8 days. In hospital-recruited patients, this 
estimate was more than 50 times higher. The relative impact of adjustment for comorbid conditions and exacerbations of respiratory symptoms was larger in the former group. Our findings also emphasise the need to estimate disease burden in population-based surveys, and to base economic evaluations on population-based studies rather than evaluations piggybacked on randomised clinical trials.

Acknowledgements The authors are indebted to Margrete Klemmetsby, Hege Marie Schnelle, Idunn Riisnes, Jan Egil Romestrand, Erik Helgeland, Jan Schille, Lene Svendsen, Tonje Lauvaasvaag, Heike Wiegmann and Lene Kvamsdal for their contribution in collecting the data for EconCOPD.

Contributors RG, AG, JEA and AJ were responsible for the design, planning and data collection. $R G$ and ME contributed to the data management, quality control and drafting. RG, AJ, TE and ME performed the statistical analyses. All the authors contributed to the analysis plan and revision, and all gave approval of the drafts.

Competing interests $R G$ reports grants from The Norwegian Association of Heart and Lung Patients and EXTRA funds from the Norwegian Foundation for Health and Rehabilitation, during the conduct of the study; grants and personal fees from Boehringer Ingelheim, personal fees from AstraZeneca and personal fees from GlaxoSmithKline, outside the submitted work.

Ethics approval The Regional Committee for Medical and Health Research Ethics in Western Norway (approval REK Vest nr. 252.04).

Provenance and peer review Not commissioned; externally peer reviewed.

Data sharing statement No additional data are available.

Open Access This is an Open Access article distributed in accordance with the Creative Commons Attribution Non Commercial (CC BY-NC 4.0) license, which permits others to distribute, remix, adapt, build upon this work noncommercially, and license their derivative works on different terms, provided the original work is properly cited and the use is non-commercial. See: http:// creativecommons.org/licenses/by-nc/4.0/

\section{REFERENCES}

1. The World Health Organization (WHO). Projections of mortality and causes of death, 2015 and 2030. http://www.who.int/healthinfo/ global_burden_disease/projections/en/ (accessed 26 Feb 2014).

2. Miller JD, Foster $T$, Boulanger $L$, et al. Direct costs of COPD in the U.S.: an analysis of Medical Expenditure Panel Survey (MEPS) data. COPD 2005;2:311-18

3. Nielsen R, Johannessen A, Benediktsdottir B, et al. Present and future costs of COPD in Iceland and Norway: results from the BOLD study. Eur Respir J 2009;34:850-7.

4. Jansson SA, Backman $\mathrm{H}$, Stenling $\mathrm{A}$, et al. Health economic costs of COPD in Sweden by disease severity-has it changed during a ten years period? Respir Med 2013;107:1931-8.

5. Drummond M. Cost-of-illness studies: a major headache? Pharmacoeconomics 1992;2:1-4.

6. Drummond MF, O'Brien BJ, Stoddart GL, et al. Methods for the economic evaluation of health care programmes. Oxford: Oxford University Press, 1997.

7. Allen H, Rogers W, Bunn WB III. Managing the burden of chronic obstructive pulmonary disease on workforce health and productivity: upping a leading employer's game. J Occup Environ Med 2012;54:1064-77.
8. Darkow $\mathrm{T}$, Kadlubek PJ, Shah $\mathrm{H}$, et al. A retrospective analysis of disability and its related costs among employees with chronic obstructive pulmonary disease. J Occup Environ Med 2007;49:22-30.

9. Lou P, Zhu Y, Chen P, et al. Vulnerability, beliefs, treatments and economic burden of chronic obstructive pulmonary disease in rural areas in China: a cross-sectional study. BMC Public Health 2012;12:287.

10. Montes de Oca M, Halbert RJ, Talamo C, et al. Paid employment in subjects with and without chronic obstructive pulmonary disease in five Latin American cities: the PLATINO study. Int J Tuberc Lung Dis 2011;15:1259-64, i-iii.

11. Nishimura S, Zaher C. Cost impact of COPD in Japan: opportunities and challenges? Respirology 2004;9:466-73.

12. Tinkelman D, Nordyke RJ, Isonaka S, et al. The impact of chronic obstructive pulmonary disease on long-term disability costs. J Manag Care Pharm 2005;11:25-32.

13. Wouters EF. Economic analysis of the Confronting COPD survey: an overview of results. Respir Med 2003;97(Suppl C):S3-14.

14. Nielsen R, Klemmetsby M, Gulsvik A. Economics of COPD: literature review and experiences from field work. Clin Respir $J$ 2008;2(Suppl 1):104-10.

15. Nielsen R, Johannessen A, Omenaas ER, et al. Excessive costs of COPD in ever-smokers. A longitudinal community study. Respir Med 2011;105:485-93.

16. Sorheim IC, Johannessen A, Grydeland TB, et al. Case-contro studies on risk factors for chronic obstructive pulmonary disease: how does the sampling of the cases and controls affect the results? Clin Respir J 2010;4:89-96.

17. Gulsvik A, Tosteson T, Bakke P, et al. Expiratory and inspiratory forced vital capacity and one-second forced volume in asymptomatic never-smokers in Norway. Clin Physiol 2001;21:648-60.

18. ATS. Standardization of Spirometry, 1994 Update. American Thoracic Society. Am J Respir Crit Care Med 1995;152: 1107-36.

19. Anthonisen NR, Manfreda J, Warren CP, et al. Antibiotic therapy in exacerbations of chronic obstructive pulmonary disease. Ann Intern Med 1987;106:196-204.

20. Charlson ME, Pompei P, Ales KL, et al. A new method of classifying prognostic comorbidity in longitudinal studies: development and validation. J Chronic Dis 1987;40:373-83.

21. Jansson SA, Andersson F, Borg S, et al. Costs of COPD in Sweden according to disease severity. Chest 2002;122:1994-2002.

22. Marrie RA, Dawson NV, Garland A. Quantile regression and restricted cubic splines are useful for exploring relationships between continuous variables. J Clin Epidemiol 2009;62:511-17.e1.

23. Lindberg A, Bjerg A, Ronmark E, et al. Prevalence and underdiagnosis of COPD by disease severity and the attributable fraction of smoking report from the obstructive lung disease in Northern Sweden studies. Respir Med 2006:100:264-72.

24. Waatevik M, Skorge TD, Omenaas E, et al. Increased prevalence of chronic obstructive pulmonary disease in a general population. Respir Med 2013;107:1037-45.

25. Jansson SA, Lindberg A, Ericsson A, et al. Cost differences for COPD with and without physician-diagnosis. COPD 2005;2:427-34

26. Evans C, Crawford B. Patient self-reports in pharmacoeconomic studies. Their use and impact on study validity. Pharmacoeconomics 1999;15:241-56.

27. Nielsen R. Costs of chronic obstructive pulmonary disease in a general population. Methodological aspects and longitudinal perspectives [dissertation]. Bergen: University of Bergen, 2011

28. Statistics Norway. Labour force survey, seasonally-adjusted monthly figures. https://www.ssb.no/en/arbeid-og-lonn/statistikker/akumnd (accessed 26 Feb 2014).

29. Rutten-van Molken MP, Goossens LM. Cost effectiveness of pharmacological maintenance treatment for chronic obstructive pulmonary disease: a review of the evidence and methodological issues. Pharmacoeconomics 2012;30:271-302. 


\section{Correction}

Erdal M, Johannessen A, Askildsen JE et al. Productivity losses in chronic obstructive pulmonary disease: a population-based survey. BMJ Open Resp Res 2014;1:e000049. doi:10.1136/ bmjresp-2013-000049

The second sentence of the Design section of the article has been amended to read: The latter were defined by an increase in two major symptoms (dyspnoea, sputum volume or sputum colour) or one major and one minor symptom (cough, sore throat, nasal secretion, wheezing or asthaenia) for at least two consecutive days (modified Anthonisen criteria).

BMJ Open Resp Res 2016;3:e000049corr1. doi:10.1136/bmjresp-2014-000049corr1 